\title{
Application of urine cells in drug intervention for spinal muscular atrophy
}

\author{
QI-JIE ZHANG ${ }^{1 *}$, XIANG LIN ${ }^{1 *}$, JIN-JING LI $^{1}$, YING-QIAN LU ${ }^{1}$, XIN-XIN GUO ${ }^{1}$, \\ EN-LIN DONG ${ }^{1}$, MIAO ZHAO ${ }^{1}$, JIN HE ${ }^{1}$, NING WANG ${ }^{1,2}$ and WAN-JIN CHEN ${ }^{1,2}$ \\ ${ }^{1}$ Department of Neurology and Institute of Neurology, First Affiliated Hospital; \\ ${ }^{2}$ Fujian Key Laboratory of Molecular Neurology, Fujian Medical University, Fuzhou, Fujian 350005, P.R. China
}

Received August 2, 2016; Accepted May 5, 2017

DOI: $10.3892 /$ etm.2017.4791

\begin{abstract}
Spinal muscular atrophy (SMA) is a lethal childhood neurodegenerative disorder that is caused by the homozygous deletion of survival motor neuron 1 (SMN1). To date, no effective treatments are available. In the current study, urine cells taken from SMA patients were cultured and the application of patient-derived urine cells was determined in drug intervention. A total of 13 SMA patient-derived urine cell lines and 40 control cell lines were established. SMN was highly expressed in the nucleus and cytoplasm. Patient-derived urine cells expressed low levels of SMN protein compared with controls, they exhibited good tolerance to chemical and electrical damage. SMN expression was upregulated following treatment with histone deacetylase inhibitors and the effect was greater in groups treated with morpholino modified antisense oligo, which targets ISS-N1 in SMN2 intron 7. The results of the current study indicated that SMA patient-derived urine cells may be useful in the initial screening of potential compounds and drugs to treat SMA.
\end{abstract}

\section{Introduction}

Spinal muscular atrophy (SMA) is a lethal neurological genetic disorder that occurs in infancy. There are three types of childhood onset SMA, classified according to age of onset and motor function: SMA I, II and III (1). Patients with SMA I, the most severe type, usually develop muscular weakness before reaching 6 months and succumb to respiratory failure

Correspondence to: Dr Wan-Jin Chen, Department of Neurology and Institute of Neurology, First Affiliated Hospital, Fujian Medical University, 20 Chazhong Road, Fuzhou, Fujian 350005, P.R. China

E-mail:wanjinchen75@fjmu.edu.cn

*Contributed equally

Key words: spinal muscular atrophy, urine cells, histone deacetylase inhibitors, antisense oligo, drug intervention before the age of 2 . In mainland China, the prevalence of SMA is $\sim 1.4$ in 10,000 and the carrier frequency is estimated to be 1 in 42 (2). To date, no effective treatments for SMA are available.

The SMA-determining gene, survival of motor neuron 1 (SMN1) was initially identified in 1995 (3). SMN2, a highly identical homolog to SMN1 in 5q13 has also been identified, encoding a majority of the truncated SMN protein $(\Delta 7-\mathrm{SMN})$ that results from the abnormal splicing of exon 7 during transcription (3). The SMN2 gene is unique to humans and modifies the disease severity of SMA, thus representing a promising therapeutic target. Different types of drugs stimulating the inclusion of exon 7 in SMN2 have been identified, including histone deacetylase inhibitors (HDACi), hydroxyurea, ceftriaxone, antisense oligo and novel synthetic compounds (4-6). The efficacy of valproic acid has been assessed in clinical trials, however the results are controversial, as both positive and negative results were observed in SMA patients from different clinical trials (7-11).

SMA is a genetic disease, thus the acquisition of SMA patient-derived cell samples may function as a tool for molecular research and drug intervention. However, although patient-derived fibroblasts are currently used widely in research to assess the mechanism of a number of neurological disorders, muscle or skin biopsy procedures are invasive and usually unacceptable for young patients with SMA clinically. Previously, urine cell lines have been successfully established from urine sediments (12). In the present study, urine sediments from different patients with SMA were cultured and patient-derived urine cell lines were established in vitro. Using these stable urine cell lines, HDACi and antisense oligo intervention was performed, aiming to investigate the application of urine cells in screening the efficacy of potential drugs to treat SMA.

\section{Materials and methods}

Primary urinary cell culture. Urine sediment culture was performed following a previously described protocol (12). All recruited patients fulfilled the clinical and genetic diagnostic criteria for SMA with homozygous deletion of SMN1 gene (13). A total of 13 patients with SMA (12 males and 1 female; age range, 1.5-39 years) were recruited in the 
current study between June 2011 and September 2013 from the First Affiliated Hospital of Fujian Medical University (Fuzhou, China). A total of 40 control urine cell lines were cultured, using the same culture method, from control subjects (36 males and 4 females, aged 5-62 years) without SMA disease at the same period (June 2011 to September 2013) from the First Affiliated Hospital of Fujian Medical University (Fuzhou, China). The present study was approved by the Ethics Committee of First Affiliated Hospital of Fujian Medical University and written informed consent was obtained from all participants or their parents.

Valproic acid (VPA) and Suberoylanilide hydroxamic acid (SAHA) intervention. A total of 13 SMA urine cell lines were produced from different patients. The majority of the urine cell lines consisted of fusiform cells with similar cell growth rates. The current study used 4 randomly selected cell lines with similar cell morphological features (fusiform, SMA-01, SMA-02, SMA-03, SMA-13) for drug intervention. All cell lines adopted for further drug intervention were expanded for 2 or 3 passages with a similar cell growth rate. VPA (Sigma-Aldrich; Merck KGaA, Darmstadt, Germany) and SAHA (Sigma-Aldrich; Merck KGaA) were administrated in a dose- and time-dependent manner. The final concentrations of VPA were $0,5,10,15$ and $20 \mathrm{mM}$ and the final concentrations of SAHA were $0,0.5,1,5$ and $10 \mu \mathrm{M}$. Following incubation with the stated concentrations of VPA and SAHA for 24, 48 and $72 \mathrm{~h}$, morphological changes in the cells were observed and SMN expression was quantified. All experiments were repeated at least three times. The concentration of VPA and SAHA was adopted according to previous studies $(14,15)$.

Morpholino modified antisense oligo (ASO) intervention. A previous study observed that morpholino-ASO was able to significantly increase the expression of SMN protein (16). Therefore, morpholino-ASO was purchased from Gene Tools, LLC, Philomath, OR, USA). The morpholino-ASO sequence was ATTCACTTTCATAATGCTGG, targeting intronic splicing silencer N1 (ISS-N1) in SMN2 intron 7. SMA-01 and SMA-13 cell lines were adopted. The doses of ASO used were 0, 10, 20 and $40 \mathrm{pmol} /$ well. Morpholino-ASO intervention was performed using an electroporator (BEX CO., LTD., Tokyo, Japan) and Opti-MEM (Gibco; Thermo Fisher Scientific, Inc.) was used as an electroporation medium, with a final volume of $30 \mu \mathrm{l} /$ well. The parameters of electroporation were: Poration pulse $(\mathrm{Pp}) \mathrm{V}, 150 \mathrm{~V}$; Driving pulse (Pd) V, 20 V; Pd cycle, 10; Pp on, 10.0 msec; Pd on, 50.0 msec; Capacity (Capa), 1416.3 uF; Pp off, $10.0 \mathrm{msec}$ and Pd off, $50.0 \mathrm{msec}$. Following electroporation, urine cells were seeded onto 12 -well plates with $3 \times 10^{4}$ cells/well in epithelial cell medium (ScienCell Laboratories, Inc.) at $37^{\circ} \mathrm{C}$ for $6 \mathrm{~h}$. After $6 \mathrm{~h}$, the medium was switched to fresh epithelial cell medium (ScienCell Laboratories, Carlsbad, CA, USA). SMN protein was harvested 24, 48 and $72 \mathrm{~h}$ after seeding. All experiments were repeated at least three times.

Cell toxicity analysis to assess the rate of cell death. To investigate the toxicity of VPA and SAHA in urine cells, the current study used $50 \mathrm{mM} \mathrm{VPA}$ and $20 \mu \mathrm{M}$ SAHA to treat urine cells and observed the cell morphological changes and cell mortality rates using a Trypan blue staining cell viability assay kit (catalogue no. C0011; Beyotime Institute of Biotechnology, Shanghai, China) following the manufacturers protocol. The number of trypan blue positive cells was calculated using a hemocytometer (Shanghai Precision Instruments Co., Ltd, Shanghai, China) under an inverted microscope (IX71; Olympus Corporation, Tokyo, Japan). The ratio of trypan blue positive cells to total cells when seeded was then calculated.

SMN-specific protein cell immunoassay. The cell immunoassay was performed as previously described by Sumner et al (17), with minor modifications. Briefly, urine cells were digested and seeded onto 96-well plates with $2-3 \times 10^{3}$ cells/well. When cell density reached $\sim 80 \%$, VPA and SAHA were added and incubated for $24 \mathrm{~h}, 48 \mathrm{~h}$ and $72 \mathrm{~h}$. At each different time point, cells were fixed with $2.5 \%$ formaldehyde (at room temperature for $30 \mathrm{~min}$ ) and permeabilized with $0.1 \%$ Triton-X-100 (at room temperature for $5 \mathrm{~min}$ ) in phosphate-buffered saline (PBS). Following blocking with 5\% non-fat milk (at room temperature for $1 \mathrm{~h}$ ), cells were incubated with anti-SMN1 rabbit polyclonal antibody (1:500; GTX101047; GeneTex, Inc., Irvine, CA, USA) at $4^{\circ} \mathrm{C}$ overnight and were subsequently probed with peroxidase-conjugated goat anti-rabbit immunoglobulin G (IgG; ZF-0516, ZSGB-BIO Technology, Co., Ltd., Beijing, China) at $37^{\circ} \mathrm{C}$ for $2 \mathrm{~h}$. Tetramethyl benzidine developing solution (Promega Corporation, Madison, WI, USA) was added and $15 \mathrm{~min}$ later, the reaction was attenuated using $2 \mathrm{~mol} / \mathrm{L} \mathrm{H}_{2} \mathrm{SO}_{4}$. Optical density values were measured at $490 \mathrm{~nm}$ using an ELISA reader (Bio-Rad, Laboratories, Inc., Hercules, CA, USA) and were further analysed using Excel software (Office, Version 10.1.0.6393; Microsoft Corporation, Redmond, WA, USA).

Western blotting. Urine cells were seeded onto 6-well plates at a density of $3-5 \times 10^{4}$ cells/well with epithelial cell medium at $37^{\circ} \mathrm{C}$ for $24 \mathrm{~h}$. When cell confluence reached $\sim 80 \%$, total proteins were extracted by cell lysis buffer for western blot (catalogue no. P0013; Beyotime Institute of Biotechnology). Briefly, $100 \mu 1$ cell lysis buffer was added to each well to split the cells on ice for $10 \mathrm{sec}$. Lysis buffer was collected and centrifuged at $12,000 \mathrm{x} \mathrm{g}$ for $5 \mathrm{~min}$ at $4^{\circ} \mathrm{C}$ to harvest the supernatant. The supernatant was subsequently denatured at $100^{\circ} \mathrm{C}$ in water for $10 \mathrm{~min}$. The protein concentration was determined using the BCA protein assay kit (catalogue no. P0012S; Beyotime Institute of Biotechnology) following manufacturers protocol, using a microplate reader (SpectraMax M5; Olympus Corporation, Tokyo, Japan) according to the manufacturer's protocol. Proteins (20 $\mu$ l per lane) were separated using 12\% SDS-PAGE and transferred to nitrocellulose membranes (GE Healthcare, Chicago, IL, USA). The membrane was blocked at room temperature for $1 \mathrm{~h}$ using 5\% skimmed milk in Tris- $\mathrm{HCl}$ buffer. It was then probed with rabbit polyclonal SMN1 antibody (1:500; catalogue no. GTX101047; GeneTex, Inc.) and mouse monoclonal Actin antibody (1:20,000; catalogue no. AA128; Beyotime, Nantong, Jiangsu, China) overnight at $4^{\circ} \mathrm{C}$. Peroxidase-conjugated goat anti-rabbit (catalogue no. ZB-2301; ZSGB-Bio, Technology, Co., Ltd.) and mouse 
Table I. Origins and cell morphological features of 13 cell lines from patients with SMA.

\begin{tabular}{lcll}
\hline $\begin{array}{l}\text { Cell } \\
\text { lines }\end{array}$ & $\begin{array}{c}\text { Age, } \\
\text { years }\end{array}$ & Sex & $\begin{array}{l}\text { Morphological } \\
\text { features }\end{array}$ \\
\hline SMA-01 & 17 & Male & Fusiform \\
SMA-02 & 22 & Male & Fusiform \\
SMA-03 & 14 & Male & Fusiform \\
SMA-04 & 1.5 & Male & Round \\
SMA-05 & 1.5 & Male & Fusiform \\
SMA-06 & 35 & Male & Round \\
SMA-07 & 3 & Male & Fusiform \& round \\
SMA-08 & 10 & Male & Fusiform \\
SMA-09 & 2 & Female & Round \\
SMA-10 & 29 & Male & Fusiform \\
SMA-11 & 15 & Male & Fusiform \\
SMA-12 & 30 & Male & Fusiform \\
SMA-13 & 39 & Male & Fusiform
\end{tabular}

SMA; Spinal muscular atrophy. Different cellular morphological features correlated with different cell type; Type-1 primarily consisted with rounded cells; Type- 2 primarily consisted with fusiform cells. The type- 2 cells could subculture more passages than type- 1 . The cell growth rate was similar between type-1 and type- 2 . These results were described previously (12).

IgG (ZB-2305, ZSGB-Bio, Technology, Co., Ltd.) were used as secondary antibodies at a dilution of $1: 2,000$ at $37^{\circ} \mathrm{C}$ for $2 \mathrm{~h}$. Images were acquired using darkroom development techniques for chemiluminesence (BeyoECL Plus A and B solution; Beyotime Institute of Biotechnology). The ratio of SMN to Actin was calculated using QuantityOne software, version 4.6.2 (Bio-Rad Laboratories, Inc.).

Immunofluorescence staining. Urine cells (SMA-01 and control-01) were seeded onto cover slips in a 6-well dish ( $1 \times 10^{4}$ cells/slip). The adherent cells were then fixed with $4 \%$ paraformaldyde (at room temperature for $30 \mathrm{~min}$ ) and were blocked with $10 \%$ goat serum in PBS (at room temperature for $1 \mathrm{~h}$ ). Cells were then probed using a SMN1 mouse monoclonal antibody (1:50; catalogue no. sc-32313; Santa Cruz Biotechnology, Inc., Dallas, TX USA) at $4^{\circ} \mathrm{C}$ overnight. Alexa Fluor 594 conjugated affinipure goat anti-mouse IgG $(\mathrm{H}+\mathrm{L})$ (1:200; catalogue no. ZF-0513; ZSGB-Bio, Technology, Co., Ltd.) was used as the secondary antibody incubated at room temperature for $2 \mathrm{~h}$. Cell nuclei were counterstained with 4', 6-diamidino-2-phenylindole. The cover slips were mounted and visualized using a confocal microscope (Leica TCS SP5; Leica Microsystems GmBH, Wetzlar, Germany).

Statistical analysis. One-way ANOVA followed by least significant difference post hoc analysis was performed and assessed using SPSS version 16.0 (SPSS, Inc., Chicago, IL, USA) to analyse the SMN protein variation between drug-treated and control groups. $\mathrm{P}<0.05$ was determined to represent statistically significant differences.
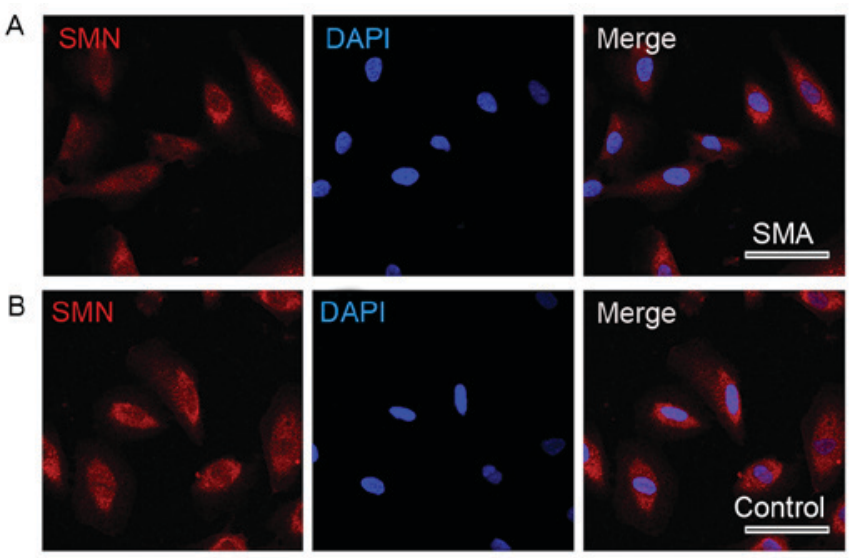

C

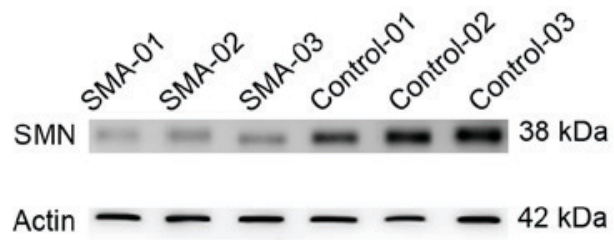

D

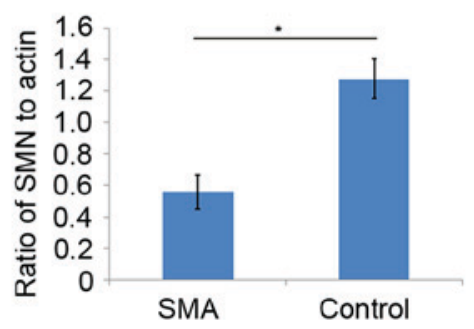

Figure 1. Cellular localization and expression of SMN in urine cells from SMA patients and those from controls. (A) SMN protein (red) was highly expressed in the nucleus and cytoplasm in SMA urine cells and a (B) similar distribution of SMN protein was observed in control urine cells. Scale bars $=50 \mu \mathrm{m}$. (C) Detection of total SMN protein in urine cells by western blotting. (D) Levels of SMN were quantified and expressed as the mean \pm standard deviation relative to actin. SMA, 0.56 \pm 0.11 ; Control, $1.28 \pm 0.12$. ${ }^{*} \mathrm{P}<0.05$ vs. control. SMA, Spinal muscular atrophy; SMN, survival motor neuron 1.

\section{Results}

SMN protein expression and localization in urine cells. The current study established 13 urine cell lines from 13 different patients with SMA (Table I) and 40 urine cell lines from controls. SMN protein was highly expressed in the nucleus and cytoplasm both in SMA and control urine cells (Fig. 1A and B). Total levels of SMN protein were determined by western blotting (Fig. 1C), which demonstrated that urine cells derived from patients with SMA expressed significantly lower levels of SMN compared with controls ( $\mathrm{t}=7.522, \mathrm{P}=0.002$; Fig. 1D).

HDACi intervention on urine cells. To determine the application of urine cells in drug interventions, small molecular compounds known as HDACi, including VPA and SAHA were used. Cell death were observed in groups treated with $50 \mathrm{mM}$ VPA $(54 \pm 7 \%)$ and $20 \mu \mathrm{M}$ SAHA $(49 \pm 7 \%)$, indicating that high doses of HDACi induce toxicity in vitro. At concentrations of $0,5,10,15$ and $20 \mathrm{mM}$, VPA did not increase levels of SMN significantly after 24, 48 and $72 \mathrm{~h}$ treatment (Fig. 2A-C). By contrast, levels of SMN significantly increased following $24 \mathrm{~h}$ treatment with $0.5,1,5$ and $10 \mu \mathrm{M}$ SAHA (all $\mathrm{P}<0.05$ ); 

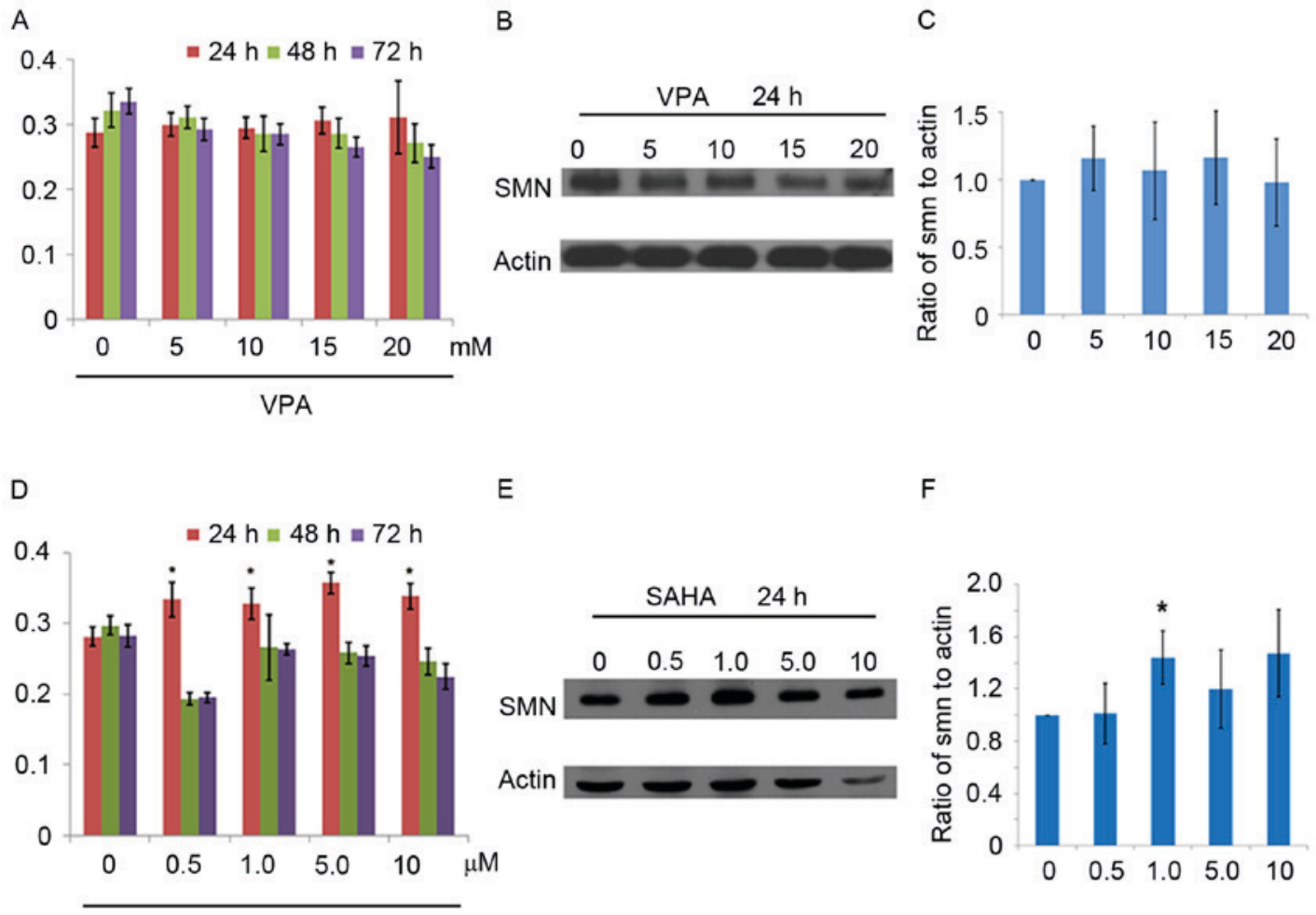

$\mathrm{F}$

SAHA

Figure 2. VPA and SAHA interventions in SMA-01 urine cells. (A) Detection of SMN protein in VPA-treated groups at $24 \mathrm{~h}, 48 \mathrm{~h}$ and $72 \mathrm{~h}$ by SMN-specific protein cell immunoassay. Data in the graphs are presented as the mean \pm SD. (B) Western blot of SMN expression in VPA-treated groups. (C) Quantification of SMN expression in VPA-treated groups following $24 \mathrm{~h}$ incubation. SMN protein expression is presented as the mean \pm SD percentage relative to actin (\%): $0 \mathrm{mM}, 100 \%$; $5 \mathrm{mM}, 115.9 \pm 23.7 \% ; 10 \mathrm{mM}, 106.7 \pm 36.1 \% ; 15 \mathrm{mM}, 116.5 \pm 34.3 \% ; 20 \mathrm{mM}, 98.0 \pm 32.0 \%$. (D) Detection of SMN protein expression in SAHA-treated groups by SMN-specific protein cell immunoassay. (E) Variation of SMN levels following $24 \mathrm{~h}$ incubation with SAHA. (F) Levels of SMN were quantified and expressed as the mean \pm SD percentage relative to actin (\%): $0 \mu \mathrm{M}, 100 \% ; 0.5 \mu \mathrm{M}, 101.3 \pm 23.3 \% ; 1 \mu \mathrm{M}, 144.1 \pm 20.2 \% ; 5 \mu \mathrm{M}, 119.8 \pm 30.0 \%$; $10 \mu \mathrm{M}, 147.3 \pm 33.5 \%$. ${ }^{\mathrm{P}}<0.05$. SD, standard deviation; SMA, Spinal muscular atrophy; SMN, survival motor neuron 1.

however, the drug-induced effects of SAHA were reversed following the longer treatment times of 48 and $72 \mathrm{~h}$ (Fig. 2D). Expression of SMN increased significantly in the group treated with $1.0 \mu \mathrm{M}$ SAHA (P<0.05; Fig. 2E and F). Similar VPA and SAHA intervention results were also observed in SMA-02, SMA-03 and SMA-13 urine cell lines (data not shown).

Morpholino-ASO intervention in urine cells. Morpholino-ASO interventions on urine cells (SMA-01 and SMA-13 lines) were performed using an electroporator. The majority of urine cells were sustained in stable cell morphology following electrical trauma, indicating that the urine cells were able to tolerate physical damage (Fig. 3A and B). Compared with the control group ( 0 pmol), levels of SMN expression significantly increased by $51.0,51.4$ and $94.6 \%$ in the groups treated with 10,20 and 40 pmol morpholino-ASO, respectively in the SMA-01 cell line (all $\mathrm{P}<0.05$; Fig. $3 \mathrm{C}$ and D). Similar ASO intervention results were observed in the SMA-13 cell line (data not shown).

\section{Discussion}

In the present study, 13 SMA patient-derived non-invasive urine cell lines were successfully cultured. The urine cells grew robustly in vitro, carried SMN gene mutations (12) and expressed low levels of SMN. Furthermore, they exhibited tolerance to small molecular compounds and electrical trauma, demonstrating that they may be used effectively in drug interventions.

There have been large advances in the field of SMA therapy, including the use of small-molecule drugs, RNA-based therapy, $S M N$ gene correction and stem cell-based cell replacement $(1,18)$. Previous studies have demonstrated that as a first-generation HDACi, VPA is able to increase SMN2 expression in SMA patient-derived fibroblasts, reduce the degeneration of motor neurons and increase motor function in mice with SMA $(14,19,20)$. In a clinical trial, Weihl et al $(7)$ reported that 7 patients with type III/IV SMA who were treated with VPA experienced an increase in muscle strength and motor function. However, in several subsequent large clinical trials, VPA or VPA + L-carnitine failed to improve the muscle strength or motor abilities of patients with SMA (8-11). SAHA is an orally administered HDACi used to treat cutaneous $\mathrm{T}$ cell lymphomas that was approved by FDA in 2006 (21). As a second-generation HDACi, SAHA may suppress type I and type II HDACi, while VPA only suppresses type I HDACi selectively (22). SAHA may activate the SMN2 gene more effectively than VPA and ameliorate the SMA phenotype in mouse models of SMA $(15,23,24)$. The results of the current study further supported the hypothesis that SAHA appears to be more efficient than VPA in increasing SMN protein expression in urine cells.

ASO, a type of RNA-based therapy, is able to significantly increase expression of SMN. ASO can effectively block 
A

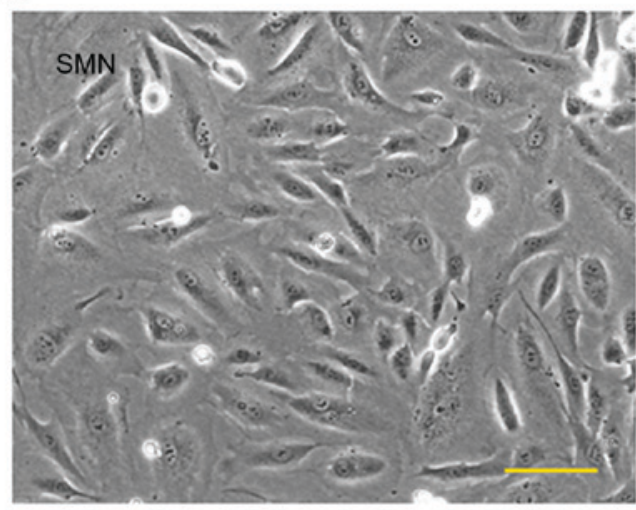

C

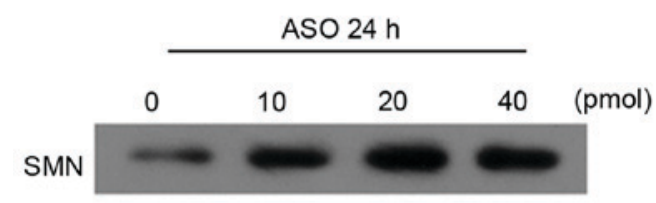

Actin

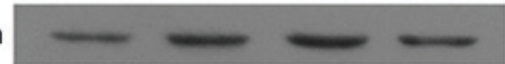

B

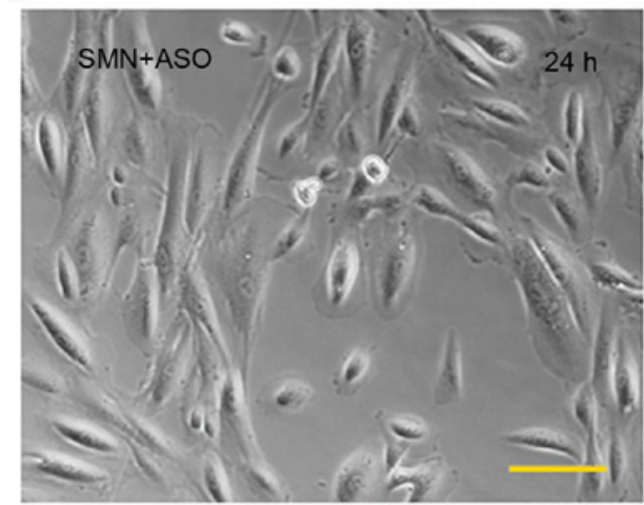

$\mathrm{D}$

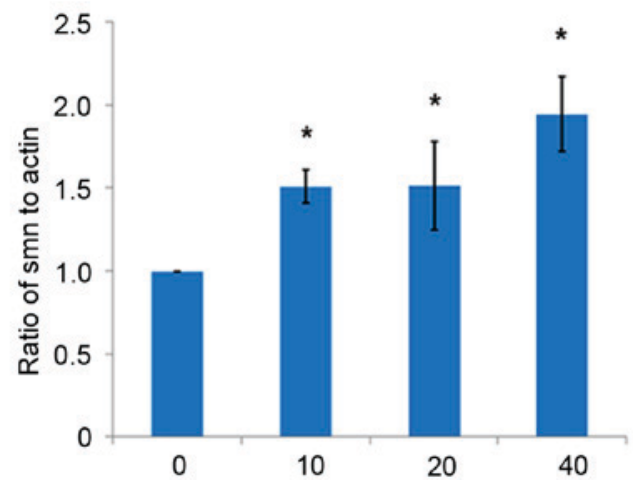

Figure 3. Morpholino-ASO interventions on the SMA-01 urine cell line. (A) Cellular morphology of urine cells (A) prior to electroporation and (B) $24 \mathrm{~h}$ after electroporation. (C) Detection of SMN protein levels following $24 \mathrm{~h}$ treatment with ASO by western blotting. (D) SMN protein expression was quantified and expressed as the mean \pm standard deviation percentage relative to actin (\%): 0 pmol, $100 \% ; 10 \mathrm{pmol}, 151.0 \pm 10.0 \% ; 20 \mathrm{pmol}, 151.4 \pm 26.9 \% ; 40 \mathrm{pmol}$, 194.6 $\pm 22.3 \%$. $\mathrm{P}<0.05$. Scale bars=100 $\mu \mathrm{m}$. ASO, antisense oligo-treated; SMA, Spinal muscular atrophy; SMN, survival motor neuron 1.

targeted exon splice enhancers (ESEs) or intronic splicing silencers (ISSs) within SMN2, including element 1, exonic splicing silencers A, exonic splicing silencers B, ISS-N1 and ISS $+100(25,26)$. The negative regulator ISS-N1 is the most effective at increasing the expression of SMN $(16,26)$. Previous studies have demonstrated that peripheral and intracerebroventricular administrations of ASO may render the inclusion of exon 7, upregulate the SMN protein expression, rescue the motor neuron function, and extend the lifespan in SMA mouse model $(27,28)$. ASO interventions are also effective at the age of onset, even following the onset of neurological symptoms in SMA mice (29). Few studies have been performed on cell samples derived from patients with SMA. Thus the current study performed ASO intervention in urine cells taken from patients with SMA, and demonstrated that ASO may significantly upregulate SMN expression.

The primary limitation of the current study is that urinary epithelial cells are a non-neural cell type. However, as a type of patient-derived somatic sample, urine cells carry $S M N$ gene mutations and express a relatively low level of SMN protein. Compared with obtaining patient-derived neurons, the urine cell culture process is simple and non-invasive; thus urine cells may be used as a platform for drug intervention and provide initial evidence indicating whether a candidate drug to treat SMA is able to upregulate the expression of SMN in cells derived from patients with SMA.
In conclusion, the results of the current study indicate that urine cells derived from patients with SMA exhibit tolerance to chemical and physical damage, which may be useful in the initial screening of potential compounds and drugs to treat SMA.

\section{Acknowledgements}

The authors wish to thank each patient and their parents for their participating in the current study. The current study was supported by the National Natural Science Foundation of China (grant nos. 81322017, 81371261 and U1505222) and the Program for New Century Excellent Talents in University, National Key Clinical Specialty Discipline Construction Program and Key Clinical Specialty Discipline Construction Program of Fujian (grant no. NCET-13-0736).

\section{References}

1. Kolb SJ and Kissel JT: Spinal muscular atrophy: A timely review. Arch Neurol 68: 979-984, 2011.

2. Sheng-Yuan Z, Xiong F, Chen YJ, Yan TZ, Zeng J, Li L, Zhang YN, Chen WQ, Bao XH, Zhang C and Xu XM: Molecular characterization of SMN copy number derived from carrier screening and from core families with SMA in a Chinese population. Eur J Hum Genet 18: 978-984, 2010.

3. Lefebvre S, Bürglen L, Reboullet S, Clermont O, Burlet $\mathrm{P}$, Viollet L, Benichou B, Cruaud C, Millasseau P, Zeviani M, et al: Identification and characterization of a spinal muscular atrophy-determining gene. Cell 80: 155-165, 1995. 
4. $\mathrm{Xu} \mathrm{C}$, Chen $\mathrm{X}$, Grzeschik SM, Ganta $\mathrm{M}$ and Wang $\mathrm{CH}$ Hydroxyurea enhances SMN2 gene expression through nitric oxide release. Neurogenetics 12: 19-24, 2011.

5. Nizzardo M, Nardini M, Ronchi D, Salani S, Donadoni C, Fortunato F, Colciago G, Falcone M, Simone C, Riboldi G, et al Beta-lactam antibiotic offers neuroprotection in a spinal muscular atrophy model by multiple mechanisms. Exp Neurol 229: 214-225, 2011.

6. Naryshkin NA, Weetall M, Dakka A, Narasimhan J, Zhao X, Feng Z, Ling KK, Karp GM, Qi H, Woll MG, et al: Motor neuron disease. SMN2 splicing modifiers improve motor function and longevity in mice with spinal muscular atrophy. Science 345 : 688-693, 2014.

7. Weihl CC, Connolly AM and Pestronk A: Valproate may improve strength and function in patients with type III/IV spinal muscle atrophy. Neurology 67: 500-501, 2006.

8. Swoboda KJ, Scott CB, Crawford TO, Simard LR, Reyna SP, Krosschell KJ, Acsadi G, Elsheik B, Schroth MK, D'Anjou G, et al: SMA CARNI-VAL trial part I: Double-blind, randomized, placebo-controlled trial of L-carnitine and valproic acid in spinal muscular atrophy. PLoS One 5: e12140, 2010.

9. Kissel JT, Scott CB, Reyna SP, Crawford TO, Simard LR, Krosschell KJ, Acsadi G,Elsheik B, Schroth MK, D'Anjou G, et al: SMA CARNIVAL TRIAL PART II: A prospective, single-armed trial of L-carnitine and valproic acid in ambulatory children with spinal muscular atrophy. PLoS One 6: e21296, 2011.

10. Darbar IA, Plaggert PG, Resende MB, Zanoteli E and Reed UC: Evaluation of muscle strength and motor abilities in children with type II and III spinal muscle atrophy treated with valproic acid. BMC Neurol 11: 36, 2011.

11. Kissel JT, Elsheikh B, King WM, Freimer M, Scott CB, Kolb SJ, Reyna SP, Crawford TO, Simard LR, Krosschell KJ, et al: SMA valiant trial: A prospective, double-blind, placebo-controlled trial of valproic acid in ambulatory adults with spinal muscular atrophy. Muscel Nerve 49: 187-192, 2014.

12. Zhang QJ, He J, Ni W, Lin X, Yao XP, Lin MT, Murong SX, Wang $\mathrm{N}$ and Chen WJ: Noninvasive urine-derived cell lines derived from neurological genetic patients. Neuroreport 24 161-166, 2013

13. Talbot K and Davies KE: Spinal muscular atrophy. Semin Neurol 21: 189-197, 2001.

14. Harahap IS, Saito T, San LP, Sasaki N, Gunadi, Nurputra DK, Yusoff S, Yamamoto T, Morikawa S, Nishimura N, et al: Valproic acid increases SMN2 expression and modulates SF2/ASF and hnRNPA1 expression in SMA fibroblast cell lines. Brain Dev 34 213-222, 2012.

15. Hahnen E, Eyüpoglu IY, Brichta L, Haastert K, Tränkle C, Siebzehnrübl FA, Riessland M, Hölker I, Claus P, Romstöck J,et al: In vitro and ex vivo evaluation of second-generation histone deacetylase inhibitors for the treatment of spinal muscular atrophy. J Neurochem 98: 193-202, 2006.

16. Porensky PN, Mitrpant C, McGovern VL, Bevan AK, Foust KD, Kaspar BK, Wilton SD and Burghes AH: A single administration of morpholino antisense oligomer rescues spinal muscular atrophy in mouse. Hum Mol Genet 21: 1625-1638, 2012.
17. Sumner CJ, Kolb SJ, Harmison GG, Jeffries NO, Schadt K, Finkel RS, Dreyfuss G and Fischbeck KH: SMN mRNA and protein levels in peripheral blood: Biomarkers for SMA clinical trials. Neurology 66: 1067-1073, 2006.

18. Lunn JS, Sakowski SA, Hur J and Feldman EL: Stem cell technology for neurodegenerative diseases. Ann Neurol 70: 353-361, 2011.

19. Sumner CJ, Huynh TN, Markowitz JA, Perhac JS, Hill B, Coovert DD, Schussler K, Chen X, Jarecki J, Burghes AH, et al: Valproic acid increases SMN levels in spinal muscular atrophy patient cells. Ann Neurol 54: 647-654, 2003.

20. Tsai LK, Tsai MS, Ting CH and Li H: Multiple therapeutic effects of valproic acid in spinal muscular atrophy model mice. J Mol Med (Berl) 86: 1243-1254, 2008.

21. Duvic M, Talpur R, Ni X, Zhang C, Hazarika P, Kelly C, Chiao JH, Reilly JF, Ricker JL, Richon VM and Frankel SR: Phase 2 trial of oral vorinostat (suberoylanilide hydroxamic acid, SAHA) for refractory cutaneous T-cell lymphoma (CTCL). Blood 109: 31-39, 2007.

22. Hauke J, Riessland M, Lunke S, Eyüpoglu IY, Blümcke I, El-Osta A, Wirth B and Hahnen E: Survival motor neuron gene 2 silencing by DNA methylation correlates with spinal muscular atrophy disease severity and can be bypassed by histone deacetylase inhibition. Hum Mol Genet 18: 304-317, 2009.

23. Riessland M, Ackermann B, Förster A, Jakubik M, Hauke J, Garbes L, Fritzsche I, Mende Y, Blumcke I, Hahnen E and Wirth B: SAHA ameliorates the SMA phenotype in two mouse models for spinal muscular atrophy. Hum Mol Genet 19: 1492-1506, 2010.

24. Somers E, Riessland M, Schreml J, Wirth B, Gillingwater TH and Parson SH: Increasing SMN levels using the histone deacetylase inhibitor SAHA ameliorates defects in skeletal muscle microvasculature in a mouse model of severe spinal muscular atrophy. Neurosci Lett 544: 100-104, 2013.

25. Nlend Nlend R, Meyer K and Schümperli D: Repair of pre-mRNA splicing: Prospects for a therapy for spinal muscular atrophy. RNA Biol 7: 430-440, 2010.

26. Pao PW, Wee KB, Yee WC and Pramono ZA: Dual masking of specific negative splicing regulatory elements resulted in maximal exon 7 inclusion of SMN2 gene. Mol Ther 22: 854-861, 2014.

27. Hua Y, Sahashi K, Rigo F, Hung G, Horev G, Bennett CF and Krainer AR: Peripheral SMN restoration is essential for long-term rescue of a severe spinal muscular atrophy mouse model. Nature 478: 123-126, 2011

28. Nizzardo M, Simone C, Salani S, Ruepp MD, Rizzo F, Ruggieri M, Zanetta C, Brajkovic S, Moulton HM, Müehlemann O, et al: Effect of combined systemic and local morpholino treatment on the spinal muscular atrophy $\Delta 7$ mouse model phenotype. Clin Ther 36: 340-356.e5, 2014.

29. Bogdanik LP, Osborne MA, Davis C, Martin WP, Austin A, Rigo F, Bennett CF and Lutz CM: Systemic, postsymptomatic antisense oligonucleotide rescues motor unit maturation delay in a new mouse model for type II/III spinal muscular atrophy. Proc Natl Acad Sci USA 112: E5863-E5872, 2015. 